\title{
CADUCIDAD DE LA RESOLUCIÓN DE CALIFICACIÓN AMBIENTAL Y REGLAMENTO DEL SEIA
}

\author{
EXPIRATION OF THE ENVIRONMENTAL QUALIFICATION \\ RESOLUTION AND SEIA REGULATION
}

\author{
Marcelo Mardones Osorio* \\ Nicolás Cannoni Mandujano*
}

\begin{abstract}
RESUMEN: En este trabajo estudiamos la caducidad de las RCA incorporada por la Ley No 20.417 de 2010 y desarrollada por el RSEIA, considerando no solo las disposiciones de la normativa ambiental, sino que teniendo presente la naturaleza jurídica de las RCA y los principios generales del Derecho Administrativo, y postulamos que las normas reglamentarias que regulan la referida caducidad han incurrido en ilegalidad al haber sido dictadas obviando disposiciones y principios esenciales de nuestro ordenamiento jurídico administrativo y general.
\end{abstract}

Palabras clave: Resolución de Calificación Ambiental, Caducidad, Sanción, Retroactividad.

ABSTRACT: This paper examines the expiry of the environmental permit (RCA) as a legal consequence incorporated by Law No20.417 and further developed by the RSEIA. It considers not only provisions of environmental regulation but also the legal nature of the RCA in connection with the general principles of Administrative Law. It suggests that regulations governing the expiry of the RCA are illegal because they ignore essential rules and principles of our administrative and general legal framework.

Key words: Environmental Qualification Resolution, Expiration, Penalty, Retroactiviness.

\section{INTRODUCCIÓN}

a) Aspectos generales Sobre las autorizaciones administrativas

Como ha señalado el Tribunal Constitucional (TC) en fallo de 16 de noviembre de $2010^{1}$ el Estado realiza distintas clases de intervenciones para regular la actividad privada. La más intensa es la prohibición completa de una actividad, cuando esta resulta totalmente incompatible con los intereses colectivos. Luego, es posible que ciertas actividades solo puedan realizarse en virtud de una concesión pública. En seguida, en otras actividades que

Doctor en Derecho (Pontificia Universidad Católica de Chile), Magíster en Ciencia Jurídica (Pontificia Universidad Católica de Chile), Máster en Asesoría Jurídica de Empresas (Instituto de Empresa, España), Diploma de Estudios Avanzados (Universidad Complutense de Madrid, España), Abogado en Aylwin, Mendoza, Luksic \& Valencia (mmardones@amlv.cl). Dirección Postal: Málaga 339, Las Condes, Santiago, Chile, Código Postal 7550255.

** Licenciado en Derecho (Pontificia Universidad Católica de Chile), Profesor Derecho Regulatorio en la Universidad Autónoma de Chile, Abogado en Aylwin, Mendoza, Luksic \& Valencia (ncannoni@amlv.cl). Dirección Postal: Málaga 339, Las Condes, Santiago, Chile, Código Postal 7550255.

1 Rosso (2010). Artículos $7^{\circ}$, inciso tercero; $8^{\circ}, N^{\circ} 5$, y 22, $N^{\circ} 3$, de la Ley $N^{\circ} 18.175$ de 1982 , Ley de Quiebras, Rol 1413-09- INA. 
encierran un riesgo potencial al interés público, el legislador somete dichas actividades a autorizaciones previas de la Administración. Y seguidamente, es posible que ciertas actividades de interés público no encierren dicho riesgo, en cuyo caso solo deben ponerse en conocimiento del Estado para poder controlarlas, sirviendo a tal fin el registro.

La autorización es un acto administrativo que tiene como finalidad la remoción de una prohibición previamente impuesta sobre derechos que el administrado poseía con anterioridad, una vez determinada la compatibilidad de dichos derechos con los intereses públicos protegidos con la prohibición previamente impuesta. De esta forma y en su construcción dogmática clásica, atribuible al jurista italiano RANELLETTI ${ }^{2}$, se suelen citar como elementos característicos de la técnica autorizatoria: (i) la existencia previa de un derecho; (ii) la existencia de una prohibición general previa sobre actividades que el ordenamiento jurídico considera como propias de los particulares; y, (iii) el levantamiento de la prohibición, previo análisis de que el derecho que se pretende ejercer es compatible con el interés público que la prohibición tutela. Así, la autorización cumple una función de remoción al levantar las prohibiciones de ejercicio que pesan sobre determinados derechos preexistentes, tras el análisis de que la actividad es compatible con los fines que justificaron la prohibición general previa ${ }^{3}$.

Junto a la función de remoción aludida, ha de añadirse una función solutoria, en tanto que viene a resolver un supuesto conflicto de intereses entre el derecho del particular, que tiende a ser ejercitado, y la Administración, que tiende a tutelar un interés público amenazado y quizás presumiblemente lesionado con un incontrolado ejercicio de aquel derecho ${ }^{4}$.

En virtud de dichas consideraciones e inspirados por las construcciones de RANELLETTI, la doctrina suele coincidir en que la autorización se diferencia de la concesión esencialmente en que esta última establece de forma nueva un derecho a favor del administrado, sobre la base de una titularidad originaria de dicho derecho por parte del Estado; mientras que la autorización solo se limita a la remoción de una prohibición previa para el ejercicio de un derecho preexistente de titularidad del autorizado.

Sin embargo, los elementos expuestos han tendido a difuminarse. Dicha dilución ha afectado especialmente a la preexistencia de un derecho como elemento determinante de la estructura tipológica de la autorización ${ }^{5}$, generando un acercamiento entre esta figura y la concesión administrativa ${ }^{6}$.

\footnotetext{
2 Desarrollada en sus siguientes trabajos: RANELleTti (1894a) pp. 7-83; (1894b) pp. 3-100, y 315-372 (1895) pp. 3-107, 255-337 (1896) pp. 77-172, 350-379; y (1897) pp. 177-277.

3 Rosso (2010). Artículos $7^{\circ}$, inciso tercero; $8^{\circ}, \mathrm{N}^{\circ} 5$, y 22, $\mathrm{N}^{\circ} 3$, de la Ley $\mathrm{N}^{\circ} 18.175$ de 1982 , Ley de Quiebras, Rol 1413-09- INA

4 Martín (1965) p. 212.

5 Elemento el cual ya había sido cuestionado por Otto MAYer (1895) p. 289, quien estimaba que el dato de la preexistencia de un derecho no era determinante tipológico de la autorización. Para dicho autor, la autorización administrativa era caracterizable esencialmente como una dispensa de prohibición (Entbindung vom Verbote).

6 García de Enterría y Fernández (2006) pp. 136-138; Santamaría (2005) pp. 263-264; Laguna de Paz (2006) pp. 83-91; Vergara (2004b) pp. 46-47; García (1997) pp. 338-342; Cea (1991) pp. 486-487; FernánDEZ (1967) pp. 423-425. Al respecto, asimismo, vid. el fallo del TC de 14 de noviembre de 2006, SOCIEDAD VI-
} 
Como ha destacado la doctrina ${ }^{7}$, el acercamiento ha venido de la mano de la consagración positiva de títulos de intervención con carácter híbrido, es decir, que participan de las características de la autorización y de la concesión. Así por ejemplo, se alude a las denominadas "autorizaciones-concesionales" o, en la doctrina italiana, "autorizzazioni ut

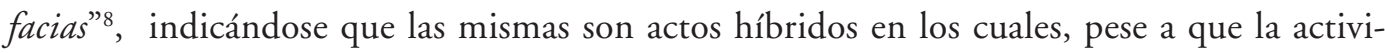
dad no ha sido objeto de una previa publificacion -no requiriéndose por tanto un título concesional-, la Administración se interesa igualmente en la actividad desarrollada por el administrado, surgiendo por ello relaciones jurídicas entre la Administración y el autorizado, de las que nacen derechos y obligaciones para ambas partes. De esta forma, en estos casos la autorización implica algo más que la remoción de obstáculos, ya que el administrado abdica de parte de su libertad al someterse a normas y directrices?

\section{b) LAS AUTORIZACIONES POR OPERACIÓN Y DE FUNCIONAMIENTO}

La doctrina suele diferenciar entre autorizaciones por operación y de funcionamiento. Desde esta perspectiva, la autorización por operación tiene por objeto una conducta determinada, cesando los efectos de la autorización una vez ejecutada, no existiendo una relación estable entre autorizado y Administración.

En cambio, las autorizaciones de funcionamiento versan sobre actividades que se desarrollan de manera prolongada en el tiempo, de lo cual surge una relación estable entre autorizado y Administración; vale decir, una relación jurídico-administrativa duradera ${ }^{10}$. Aun cuando, en contraposición con el Derecho Civil, desde el ámbito del Derecho Administrativo aún no se efectúa una clara construcción de una teoría general de la relación jurídicoadministrativa, dado que ella se ha visto opacada y postergada por los desarrollos realizados respecto de un aspecto particular de la misma (el derecho público subjetivo) ${ }^{11}$, la doctrina ha destacado que la regulación de la relación jurídico-administrativa es precisamente el objeto del Derecho Administrativo, llegando a afirmarse que dicha regulación especial es el Derecho Administrativo ${ }^{12}$.

La relación jurídico-administrativa puede tener su origen en la propia ley, en un acto administrativo, en un contrato administrativo o incluso en un acto material, y en dicha relación, es posible apreciar la existencia de 4 elementos esenciales:

Sal Ltda. Con Empresa Portuaria De ARICA (2006). Artículo 23, inciso segundo, de la Ley No 19.542 de 1997, que moderniza el sector portuario estatal. Rol 467-06.

7 García de Enterría y Fernández (2006) pp. 136-138; Vergara (2004b) pp. 46-47; García-Trevijano (1986) pp. 243-246.

8 Giglioni (2008) p. 244.

9 García-Trevijano (1986) p. 243-246.

10 Maurer (2012) p. 173; Bocanegra (2002) p. 53; García-Trevijano (1986) p. 246; Los actos administrativos que poseen efectos prolongados en el tiempo dando lugar a relaciones jurídicas duraderas (denominados por la doctrina alemana como Verwaltungsakt mit Dauerwirkung) presentan especiales dificultades en el ámbito de la invalidación y la adecuada tutela de la confianza legítima. Maurer (2012) pp.241-242. En nuestro país, JARA (2004) p. 211.

11 Martín-Retortillo (2007) pp. 293-294; pp. 316-317.

12 Maurer (2012) p. 175; Soto Kloss (2009) p. 219; García de Enterría y Fernández (2006), p. 15; MoraGA (2010) pp. 73-75. 
(i) el elemento subjetivo, conformado por las "partes" de la relación, las que suelen ser la Administración y los administrados, individual y determinadamente (o determinablemente) considerados, dado que de lo contrario, no cabe referirse a la existencia de una relación jurídica ${ }^{13}$;

(ii) el objeto, el cual tradicionalmente se define como la entidad sobre la cual recae el interés envuelto en la relación, y que en el Derecho Administrativo se refiere a los actos o conductas humanas (prestaciones, como desempeñar una función, o cumplir con un deber, como el servicio militar), así como determinadas cosas o bienes materiales (el aprovechamiento por un concesionario de un bien de dominio público);

(iii) el contenido, integrado por los poderes y deberes que la relación encierra y que constituyen su sustancia ${ }^{14}, y$;

(iv) la causa, considerada como la concurrencia de determinados hechos jurídicos regulados por el Derecho Administrativo.

La creación de la referida relación jurídico-administrativa duradera tiene como consecuencia esencial que los poderes interventores de la autoridad administrativa son mayores tanto en intensidad como en duración y tienden a garantizar que las circunstancias que motivaron la emisión de la autorización se mantengan durante el tiempo (rebus sic stantibus $)^{15}$. Para ello, la potestad autorizatoria deja de constituirse de forma reglada, para conformarse sobre la base de conceptos jurídicos indeterminados que otorgan cierto margen de apreciación o sobre diversos grados de discrecionalidad, pasando el control administrativo a ser en realidad constitutivo de un derecho que antes no podía decirse con propiedad y en rigor que existiera plenamente en la esfera del ciudadano ${ }^{16}$. De manera muy gráfica, en relación a estas autorizaciones se sostiene que:

“(...) Precisamente es esta naturaleza la que les confiere una característica muy peculiar, y es que, dado que estas autorizaciones deben disciplinar no solo lo que va a ocurrir en el momento presente, sino también lo que ocurrirá en el futuro, la autorización queda condicionada a la conservación de las circunstancias y motivos que provocaron su otorgamiento, de tal manera que la actividad en cuestión se encuentra sujeta a inspecciones de control para determinar, por un lado, si se ajusta a los requisitos en ella establecidos y, por otro, si se adecuan a las nuevas exigencias medioambientales y técnicas que vayan surgiendo..." [la negrita es nuestra] (GARCÍA, 1999, p. 140).

Esta distinción ha sido aceptada por nuestro TC en sentencia de 14 de noviembre de $2006^{17}$.

13 Maurer (2012) p. 172; Moraga (2010) p. 74.

14 Cassagne (2002) p. 350.

15 Fernandez (2006) pp. 208-209; Laguna de Paz (2006) pp. 60-67; pp. 72-73; Martín-Retortillo (1957)

p. 153; Meilán (1973) pp. 80-84; Santamaría (2005) pp. 265-267.

16 Parejo (2008) p. 283.

17 Sociedad Visal LtdaA. Con Empresa Portuaria De ARICA (2006). Artículo 23, inciso segundo, de la Ley No 19.542 de 1997, que moderniza el sector portuario estatal. Rol 467-06 


\section{NATURALEZA JURÍDICA DE LA RCA}

\section{a) LA RCA ES UN ACTO ADMINISTRATIVO}

Según variadas disposiciones de la Ley No 19.300 de 1994, de Bases del Medio Ambiente (LBMA), las RCA son resoluciones, las cuales, de acuerdo con el inciso $3^{\circ}$ del artículo $3^{\circ}$ de la Ley No 19.880 de 2003, sobre Bases de los Procedimientos Administrativos que Rigen los Órganos de la Administración del Estado (LPA), son un tipo de acto administrativo,.

Funcionalmente, de los incisos $2^{\circ}$ y $6^{\circ}$ del artículo $3^{\circ}$ de la LPA se desprende que los actos administrativos son decisiones formales que emiten los órganos de la Administración del Estado, en las cuales se contienen: (i) declaraciones de voluntad; (ii) declaraciones de juicio o dictámenes; (iii) constancias; o (iv) declaraciones de conocimiento.

La RCA es plenamente encuadrable en la categoría de los actos administrativos declarativos de voluntad, dado que en virtud de la RCA la Administración: (i) manifiesta su decisión de considerar al proyecto o actividad como conforme con la normativa ambiental vigente; y (ii) manifiesta su decisión de permitir la ejecución del proyecto o actividad en los términos autorizados ${ }^{18}$. Lo señalado se condice con que la RCA sea el resultado de un procedimiento administrativo tal y como se desprende de la letra c) del artículo 13 de la LBMA, en relación con la letra j) del artículo 2 de la misma ley. En tanto que procedimiento administrativo y en conformidad con el principio conclusivo consagrado en el artículo 8 de la LPA, dicho procedimiento está destinado a que la Administración dicte un acto decisorio que se pronuncie sobre la cuestión de fondo y en el cual exprese su voluntad.

Adicionalmente a lo anterior, debe tenerse en consideración lo dispuesto en el número 8 del artículo 17 de la Ley No 20.600 de 2012, que Crea los Tribunales Ambientales. Dicha norma consagra la categoría de los "actos administrativos de carácter ambiental", definiéndolos como toda decisión formal que emita cualquiera de los organismos de la Administración del Estado que tenga competencia ambiental y que corresponda a un instrumento de gestión ambiental o se encuentre directamente asociado con uno de estos.

\section{b) LA RCA ES UN ACTO ADMINISTRATIVO TERMINAL}

Como se señaló previamente, la evaluación de impacto ambiental es un procedimiento administrativo, que concluye con la resolución que califica ambientalmente el proyecto o actividad, i.e., con un acto terminal ${ }^{19}$. Así, dicha norma responde a la definición que al respecto contiene el artículo 18 de la LPA, que conceptualiza el procedimiento administrativo como “(...) una sucesión de actos trámite vinculados entre sí, emanados de la Administración y, en su caso, de particulares interesados, que tiene por finalidad producir un acto administrativo terminal..." [la negrita es nuestra].

18 Valencia (2009) pp. 74-75.

19 Artículo 24 de la LBMA. Asimismo, Cordero (2015) p. 269. 
Ello ha sido reconocido en forma expresa por la Corte de Apelaciones de Coyhaique $^{20}$, en fallo ratificado por la Corte Suprema ${ }^{21}$.

c) LA RCA es Un ACTO ADMinistrativo DE DOBle EFECTO

Como es sabido, los actos administrativos pueden ser favorables, cuando mejoran la posición jurídica del destinatario al otorgarle o reconocerle un derecho, una facultad, un plus de titularidad o de actuación, liberándole de una limitación, de un deber, de un gravamen, produciendo así un resultado ventajoso para el destinatario ${ }^{22}$; o de gravamen ${ }^{23}$, cuando afectan o disminuyen la esfera jurídica del ciudadano, imponiéndole una obligación o carga nuevas, reduciendo, privando o extinguiendo algún derecho o facultad hasta entonces intactos $^{24}$. Junto a ellos se encuentran los denominados actos administrativos de doble efecto (dappelwirkung), categoría que comprende aquellos actos que implican tanto medidas con efectos jurídicos favorables como de gravamen. Cuando dichos efectos se reconducen o son absorbidos por la posición jurídica del propio destinatario de la medida, se habla de actos administrativos mixtos (mischwirkung). Cuando los efectos se reparten entre el destinatario de la medida y un tercero, se alude a actos administrativos con efectos sobre terceros (drittwirkung) ${ }^{25}$, hablándose de así de resoluciones administrativas complejas. En tales casos, como ha señalado la doctrina ${ }^{26}$, se ha de regular un complejo entramado de relaciones entre diversos intereses - divergentes y convergentes, concurrentes y conflictivos-, en el que a menudo intervienen en su dictación una pluralidad de órganos de la Administración -lo que conlleva a su vez que el acto administrativo pueda considerarse como "complejo" desde la perspectiva orgánica- ${ }^{27}$. En dichos supuestos, la Administración tiene el deber de considerar por igual y de manera neutral todos los intereses concurrentes, y en ocasiones incluso a los propios interesados les pueden corresponder ciertos deberes de respeto y cargas de colaboración entre si ${ }^{28}$.

Los aspectos indicados se aprecian tanto en el artículo 25 quinquies como en el artículo 30 bis de la LBMA, que reconocen los efectos duales de la RCA, al aludir no solo al titular de la RCA, sino que asimismo a los "directamente afectados".

\footnotetext{
20 Fiscalía del Medio Ambiente y otros Cl SerVicio de EVALUACión Ambiental, Región de Aysén (2012); En este mismo sentido, vid. el fallo de la Corte de Apelaciones de Concepción de 17 de junio de 2011, I. MUNICIPALIdad de ARauco Cl Comisión de EVAluación Ambiental de la Región del Bio Bio (2011).

21 Fiscalía del Medio Ambiente y otros Cl Servicio de EVAluación Ambiental, Región de Aysén (2012).

22 García de Enterría y Fernández (2008) p. 579; García-Trevijano (1986) p. 220; Moraga (2010) p. 108.

23 Esta distinción se le suele atribuir a JeLLINEK (1908) p. 21.

24 García de Enterría y Fernández (2008) p. 579; Moraga (2010) p. 108.

25 Stober (1992) pp. 230-231; Moraga (2010) p. 111; Millar (2008) pp. 220-221; pp. 276-277.

26 Bocanegra (2002) p. 57.

27 Motivo por el cual la autorización ambiental recibe en los Derechos comparados la denominación de autorización única integrada ambiental (autorizzazione unica integrata ambientale en Italia) o simplemente como autorización ambiental integrada, en el caso de España, cuyos orígenes se sitúan en el Derecho Comunitario Europeo, concretamente, en la Directiva 96/61/CE, de 24 de septiembre, sobre prevención y control integrados de la contaminación. Virga (2001b) p. 464; Fortes (2006a) p. 736. En Chile, vid. Astorga (2007) p. 222.

28 Schmidt-Assmann (2003) pp. 184-185.
} 
d) LA RCA ES Un ACTO ADMINISTRATIVO DE CARÁCTER AUTORIZATORIO

Como se expuso previamente, en el ámbito de las RCA, y en general, tratándose de cualquier actividad económica, es posible afirmar la existencia de un derecho a la realización de tal actividad, cuyo ejercicio se encuentra limitado por las regulaciones. Junto a ello, la propia operatoria del procedimiento de evaluación ambiental y del otorgamiento de la RCA permite sostener que dicho acto administrativo es de naturaleza autorizatoria. En efecto, el artículo 8 de la LBMA señala que los proyectos o actividades señalados en el artículo 10 solo podrán ejecutarse o modificarse previa evaluación de su impacto ambiental. A su vez, de los artículos 2 letras f) y j), 16 in fine y 24 inciso $2^{\circ}$ de la LBMA se desprende que la autoridad ambiental levantará la prohibición señalada en la medida que el titular del proyecto o actividad acredite que estas cumplen con las normas ambientales vigentes.

Adicionalmente a lo anterior, la LBMA alude al carácter autorizatorio de la RCA en su artículo 25 ter, al señalar que la RCA favorable caducará “(...) cuando hubieren transcurrido más de cinco años sin que se haya iniciado la ejecución del proyecto o actividad autorizada..." [la negrita es nuestra].

\section{e) LA RCA ES UNA AUTORIZACIÓN DE FUNCIONAMIENTO}

$\mathrm{Al}$ respecto se ha señalado ${ }^{29}$ que la RCA es una autorización de funcionamiento (operativa o de tracto sucesivo), lo que supone que con su otorgamiento no se agota el vínculo entre la autoridad administrativa y el solicitante, perdurando este vínculo por un período indeterminado de tiempo. Dicha consideración parece haber sido objeto de plasmación normativa en el artículo 3 letras g) y h) de la Ley No 20.417 de 2010, que crea el Ministerio, el Servicio de Evaluación Ambiental y la Superintendencia del Medio Ambiente, en cuanto señalan como atribución de la Superintendencia de Medio Ambiente, en ambos casos “(...) Suspender transitoriamente las autorizaciones de funcionamiento contenidas en las Resoluciones de Calificación Ambiental...”.

El artículo 24 in fine de la LBMA recoge esta idea, al señalar que el titular del proyecto o actividad, durante la fase de construcción y ejecución del mismo, deberá someterse estrictamente al contenido de la RCA. Y en este mismo sentido, el artículo 25 quinquies de la LBMA reconoce que la RCA puede ser revisada, excepcionalmente, de oficio o a petición del titular o del directamente afectado, cuando ejecutándose el proyecto, las variables evaluadas y contempladas en el plan de seguimiento sobre las cuales fueron establecidas las condiciones o medidas, hayan variado sustantivamente en relación a lo proyectado o no se hayan verificado, con el objeto de adoptar medidas para corregir dichas situaciones.

Asimismo, esta conceptualización ha sido expresamente recogida por el SEA en su Ord. No130044, de 10 de enero de 2012, por medio del que se impartieron instrucciones 
sobre la elaboración de oficio de los textos refundidos, coordinados y sistematizados de las Resoluciones de Calificación Ambiental ${ }^{30}$ y por nuestros tribunales superiores de justicia ${ }^{31}$.

\section{f) LA RCA ES UNA AUTORIZACIÓN CONSTITUTIVA}

Actos administrativos constitutivos son aquellos por los que se crea, modifica o extingue una determinada situación o relación jurídica; mientras que son declarativos aquellos que, en aplicación del ordenamiento jurídico vigente, declaran de manera vinculante la existencia de un derecho, o de una determinada condición con relevancia jurídica, en una persona, cosa o situación, sin incidir sobre su contenido, o bien deniegan la pretensión de una declaración de ese tipo ${ }^{32}$.

La doctrina se encuentra dividida en relación a si la RCA sería un acto constitutivo o uno meramente declarativo ${ }^{33}$. Desde la consideración de la RCA como una autorización administrativa, a favor de esta última postura cabría argumentar que ella se condice con la construcción tradicional de las autorizaciones administrativas. Como hemos visto, la técnica autorizatoria, en su conceptualización tradicional, no tiene como consecuencia la creación de nuevos derechos a favor del autorizado, sino que simplemente permite el ejercicio de derechos preexistentes, mediante el levantamiento de una prohibición previa. Así, en la base de la autorización ambiental cabe situar la garantía constitucional del artículo 19 oo

30 “(...) La facultad de establecer el texto refundido, coordinado y sistematizado de la RCA responde a la propia naturaleza jurídica de esta resolución, que genera una relación permanente entre la autoridad y el titular del proyecto, mientras se encuentre vigente, lo que se traduce en su observancia por parte del titular y en su seguimiento y fiscalización por parte de la autoridad. Implica, asimismo, poner atención en el proyecto como una unidad, que incorpora las modificaciones que experimente en el tiempo y que se hubieren sometido al SEIA en forma independiente..." [la negrita es nuestra].

31 Sentencia de 22 de octubre de 2009, Aguas Andinas S.A., con Comisión Regional del MEdio Ambiente de la REGión Metropolitana (2009), Rol No 6312-2009, ratificado por la Corte Suprema con fecha 28 de diciembre de 2009 (Rol No8.072-09), en el cual se sostuvo: “(..) 10.- Que, el sistema de evaluación de impacto ambiental es un instrumento de gestión ambiental de carácter preventivo; en definitiva se trata de una autorización de funcionamiento con contenido ambiental, y en la especie, sujeta a las condiciones que por esta vía se impugnan..." [la negrita es nuestra]. Asimismo, vid. el fallo de fecha 18 de enero de 2013, de la Corte Suprema, Celulosa Arauco y Constitución S.A. con Comisión Regional del Medio Ambiente (2011), Rol No10.045-2011, en el que la Corte sostuvo: “(...) 9 Que necesario resulta consignar que la Resolución de Calificación Ambiental es el acto administrativo con que concluye el proceso de evaluación, cuyo contenido viene dado en los artículos 16, incisos $3^{\circ}$ y 4º, 19 inciso $3^{\circ}, 24$ y 25 de la Ley No 19.300, y que implica una autorización de funcionamiento. Que, en este orden de ideas, se aprecia que dicha resolución debe ser cumplida con apego estricto a las normas y condiciones sobre las que se aprueba el Estudio de Impacto Ambiental, de modo que el titular del proyecto es directamente responsable de adoptar las medidas que resulten ser necesarias para dar cumplimiento a la resolución que ha autorizado su funcionamiento..." [la negrita es nuestra]. Y además, vid. la Sentencia de la Corte Suprema de 22 de junio de 2015, GuaColda AdRIANA, CarRasco PÉrez Y otROS CON ENDESA (2015), Rol No23.652-2014.

32 Bocanegra (2002) p. 52; Stober (1992) p. 230; García de Enterría y Fernández (2008) p. 579.

33 Así, Fermandois (2005) p. 15, estima que la RCA es de naturaleza constitutiva, de forma que "(...) La RCA habilita a su beneficiario el desarrollo de un determinado proyecto y la ejecución de determinados actos jurídicos y materiales, bajo las condiciones ambientales que contiene...”. Por su parte, SEPúlveda (2008) p. 58, sostiene que “(...) la RCA consistiría en un acto administrativo declarativo, que declararía de forma vinculante la existencia de un derecho, ya que las facultades inherentes a desarrollar cualquier actividad económica estarían ya potencialmente en el derecho preexistente...”. Asimismo, vid. Cordero (2015) pp. 272-273. 
21 de la Constitución Política, que reconoce el derecho a desarrollar cualquiera actividad económica que no sea contraria a la moral, al orden público o a la seguridad nacional, respetando las normas legales que la regulen ${ }^{34}$. De esta manera, es posible constatar la existencia de un derecho (a desarrollar cualquier actividad económica), cuyo ejercicio se encuentra sometido a una regulación particular de naturaleza ambiental.

Sin embargo, las especiales características de la autorización ambiental permiten separarse de su consideración como una autorización, en su conceptualización tradicional de carácter declarativo. Ello, dado que con ocasión de la autorización ambiental surge una relación jurídica estable y duradera entre la Administración y el autorizado, al tratarse de una autorización de tracto sucesivo o de funcionamiento. Dicha relación tiene como consecuencia la creación de una serie de derechos y obligaciones para las partes ${ }^{35}$. En virtud de esta constatación cabe sostener que la autorización ambiental es de esas autorizaciones especiales en las que los perfiles tradicionales de dicho título habilitante se difuminan, contando con ciertas características que la acercan más bien a los títulos concesionales, en particular, en lo relativo a la creación de relaciones jurídicas. Así, la autorización ambiental no es un simple acto declarativo de un derecho preexistente, sino que se trata más bien de un acto constitutivo, en tanto que creador de una relación jurídica estable y duradera entre la Administración y el autorizado.

\section{CONSIDERACIONES GENERALES SOBRE LA CADUCIDAD}

Habiéndose analizado la naturaleza jurídica de la RCA corresponde abordar lo relativo a la institución denominada "caducidad", a fin de determinar cómo opera esta en relación a ellas, de acuerdo con la normativa legal vigente. Para ello realizaremos un análisis general de la institución para luego estudiar su régimen en la legislación ambiental.

De manera tradicional, nuestra doctrina ${ }^{36}$ ha considerado a la caducidad como una verdadera sanción. Y en este mismo sentido se ha pronunciado la jurisprudencia ${ }^{37}$. Desde dicha consideración sancionatoria, la caducidad constituye un concepto fundamental del Derecho, vinculado en forma estrecha con el concepto esencial de sanción jurídica ${ }^{38}$. La

34 Bermúdez (2013) p. 427; Virga (2001a) p. 15.

35 Vid. en este sentido el fallo de la Corte de Apelaciones de Coyhaique de fecha 3 de abril de 2014, CORPORAción Fiscalía del Medio Ambiente y otros con Comisión de EVAlUaCión Ambiental del SeRVicio de EVALUACión AMBIENTAL DE LA REGIÓN DE AYSÉN (2014), Rol No56/2013; en el que, refiriéndose a la RCA, señala que "(...) El procedimiento concluyó con un acto administrativo complejo que estableció una relación jurídica entre el titular, esto es Energía Austral, y la administración del Estado, vínculo que dura toda la vida del proyecto...”. Asimismo, vid. el fallo del Segundo Tribunal Ambiental de Santiago, de fecha 9 de agosto de 2013, DESARROllos URbanos S.A. contra la Dirección EjeCutiva del SerVicio de EVAluación Ambiental (2013), Rol R-4-2013, en el que dicho tribunal sostuvo: “(...) Es a través de la RCA, un acto administrativo de autorización, favorable, que el titular del proyecto consolida una situación jurídica determinada, naciendo derechos y obligaciones, caducando los primeros si dentro de cinco años no se inicia la ejecución del proyecto, lo que reafirma que la existencia de un proyecto es un momento previo y distinto al de su ejecución...”.

36 Lira (2009) pp. 611, 614, 622; Rodríguez (2008) p. 50; Ubilla (1990) p. 43; AlesSandri (1949) p. 337.

37 Corte Suprema, fallo de fecha 28 de noviembre de 2007, Llona CON INSTITUTO DE NoRMALIZACIÓN PREVISIONAL (2007) Rol No 4101/2007.

38 PRIETO (2008) p. 295. 
doctrina ${ }^{39}$ sostiene que la sanción jurídica constituye un acto coercitivo -de fuerza actual o potencial-, prescrito por una norma jurídica, consistente en la privación de algún bien (por ejemplo, la vida, la propiedad, la libertad, el honor, etc.) ejercida por un individuo autorizado al efecto y como consecuencia de una conducta. En dicho esquema se aprecia la existencia de: (a) un deber jurídico impuesto por una norma a cuyo incumplimiento se anuda el establecimiento de la sanción; (b) un acto antijurídico, que es aquel acto contrario al deber jurídico predispuesto y que opera como condición de la sanción; y (c) un responsable, que es quien se encuentra llamado a soportar la sanción ${ }^{40}$. Bajo dicho prisma, efectivamente, cabe comprender que la caducidad constituya una sanción jurídica, en la medida que: (a) contemple la existencia de una obligación determinada, y; (b) el incumplimiento de dicho deber conlleve una situación de privación, que en el caso de caducidad, consiste en la extinción del derecho o acción de que se trate. En tales condiciones es que la caducidad puede considerarse como una sanción que el ordenamiento jurídico impone a un titular de un determinado bien, por haber dejado de cumplir todas o algunas de las obligaciones impuestas en relación con dicho bien dentro del plazo fatalmente dispuesto al efecto, acarreando ello la extinción de la referida titularidad.

\section{LA CADUCIDAD EN EL DERECHO ADMINISTRATIVO Y AMBIENTAL}

\section{a) Aspectos generales}

En la doctrina administrativa comparada ${ }^{41}$ se señala que la caducidad administrativa es un concepto con diversas significaciones, distinguiéndose entre: (i) caducidad de acciones, pretensiones, derechos y potestades; (ii) caducidad-preclusión o caducidad de meros trámites procedimentales; y (iii) caducidad-perención o caducidad del procedimiento. En dicha clasificación se aprecia que la caducidad administrativa, al igual que la civil, puede tener efectos jurídicos tanto sobre el derecho mismo (derecho subjetivo o potestad), sobre la posibilidad de su puesta en movimiento (acción) y su movimiento en el marco del procedimiento, o directamente sobre el cauce jurídico a través del cual se desenvuelve la acción (el procedimiento). De las acepciones expuestas, interesa centrarnos en aquella que afecta la existencia de derechos o actos, dada la especial relevancia que posee en la materia que estamos tratando ${ }^{42}$.

$\mathrm{Al}$ respecto, la doctrina ${ }^{43}$ ha señalado que en el Derecho Administrativo la caducidad es un concepto aplicable respecto de derechos ya nacidos, por alguna causa legal de incumplimiento de obligaciones, operando como una sanción que extingue el respectivo derecho.

\footnotetext{
39 Ruiz-Tagle (1990) pp. 117-119; Nino (2003) p. 82.

40 Prieto (2008) pp. 295-297.

41 Tardío (2005) pp. 12-18; Soria (2003) p. 1717; González (1964) pp. 194, 197-200; Herrera y RuizTAGLE (2014) pp. 172-173.

42 En relación a la caducidad procedimental (denominada también abandono o decaimiento -sic- del procedimiento) en nuestra doctrina pueden consultarse, entre otros, Herrera y Ruiz-TAGLe (2014) pp. 172-176; CorDERO (2011) pp. 250-251; Rojas (2007) pp. 129-130; Vergara (2004a) pp. 571-572. En la doctrina española, vid. entre muchos otros, MARTín (1985) p. 389.

43 Rojas (2007) p. 130; Vergara (2004a) p. 568.
} 
Para otro sector ${ }^{44}$, la caducidad administrativa se incardina más bien dentro de los supuestos extintivos de los actos administrativos, sin perjuicio de que por la vía de la extinción del acto se produzca la extinción de una situación jurídica preexistente ${ }^{45}$. En este sentido se ha pronunciado la Contraloría General de la República (en adelante, CGR) en su dictamen $\mathrm{N}^{\circ} 89.271$, de 1966, según el cual la caducidad es una sanción que se detona en caso que el titular de determinado acto administrativo no cumpla con una obligación impuesta directamente por la ley o por el propio acto administrativo. De esta manera, los derechos derivados del acto penden de una condición resolutoria impuesta por la ley o el acto administrativo.

\section{b) SOBRE EL CARÁCTER SANCIONATORIO DE LA CADUCIDAD ADMINISTRATIVA}

En relación al carácter sancionatorio de la caducidad administrativa, este se acepta de manera generalizada por la doctrina ${ }^{46}$ y por el propio legislador ${ }^{47}$. Y así puede verificarse también en los fallos de nuestros tribunales superiores de justicia ${ }^{48}$ y en la jurisprudencia de la $\mathrm{CGR}^{49}$. Desde dicho prisma, la caducidad administrativa es una sanción que el ordenamiento jurídico impone con carácter general a todo destinatario de un acto administrativo, por haber dejado de cumplir todas o determinadas obligaciones, acarreando ello la extinción del referido acto. Por ende, la caducidad sería una forma de sanción, y como tal debe encontrarse expresamente prevista en el ordenamiento jurídico, en atención a los principios de legalidad y tipicidad que informan el Derecho administrativo sancionatorio, no pudiendo ser creada por la autoridad administrativa ${ }^{50}$.

Sin embargo, la conceptualización de la caducidad como sanción no es indubitada. $\mathrm{Al}$ respecto se ha señalado ${ }^{51}$ que tal consideración parte de una base errada, consistente en la confusión del ius puniendi del Estado con la facultad resolutoria de un acto jurídi-

\footnotetext{
44 Dromi (2008) p. 219; Soria (2003) p. 1716; CASSAgne (2002) p. 249; Virga (2001a) p. 100; PicCinini (1968) p. 26.

45 Cordero (2015) p. 315; Moraga (2010) pp. 255-256; Virga (2001a) pp. 140-141; Madariaga (1993) p. 103; PicCinini (1968) pp. 28-29.

46 Cordero (2015) p. 315; Alcalde (2013) p. 318; Moraga (2010) pp. 255-256; Rojas (2007) pp. 130-133; Vergara (2004a) p. 568; Silva (1995) p. 153; Madariaga (1994) pp. 86-88; Madariaga (1993) p. 103; PiCCININI (1968) pp. 27-28. En Argentina, también considerando la caducidad como una sanción, vid. CASSAGNE (2002) p. 249; Gordillo (2004) XIII-19. Y en España también se aprecia la consideración histórica de la caducidad como una sanción: CABAllero (1999) pp. 9-69; Rodríguez (1994) pp. 351-353. En la doctrina italiana, vid. LuPO (2013) p. 173.

47 Vid. el artículo 36 de la Ley No 18.168 de 1982, Ley General de Telecomunicaciones; o el artículo 5ª inciso final de la Ley No19.925 de 2004, sobre Expendio y Consumo de Bebidas Alcohólicas.

48 Vid. el fallo de la Corte de Apelaciones de Temuco de fecha 18 de marzo de 2008, Rol No1.575/2007, MARtínez Pita, Guadalupe Inés y otros con Alcalde de la I. Municipalidad de Pucón y el Director del Depto. DE Rentas y PATENTes MuniCipales, confirmado por la Corte Suprema, Rol No1789/2008; y el fallo de la Corte Suprema, de fecha 6 de agosto de 2012, TesorerIA REGIONAL DE ANTOFAGASTA, FisCo DE ChILE CON FLOTA BARRIOS S.A. (2010) Rol No 4777/2010.

49 Vid. los dictámenes $\mathrm{No}_{\text {s }} 19.159 / 1962 ; 89.271 / 1966 ; 25.505 / 2001$, entre otros.

50 Rojas (2007) p. 132; Navarro (2005) pp. 118-128; Vergara (2004a) pp. 568-569; Soria (2003) p. 1722; Aróstica (1991) pp. 173-195.

51 Velasco (1996) pp. 87-92; Bermúdez (1998) p. 324.
} 
co derivado del incumplimiento de sus condiciones. De esta forma, en la medida que las exigencias que dan origen a la caducidad constituyen mandatos legales, su incumplimiento sí da origen a una caducidad de carácter sancionatorio. Tratándose del incumplimiento de condiciones impuestas en el acto administrativo (i.e., elementos accesorios del acto administrativo), la caducidad que se pueda declarar carecería de dicha naturaleza. Esta posición también se puede apreciar en la doctrina italiana ${ }^{52}$, la cual diferencia entre la caducidad en sentido propio (decadenza in senso proprio), cuyos elementos constitutivos son la inercia del titular y el transcurso del tiempo, y la caducidad en sentido amplio o impropia (decadenza in senso ampio o improprio), que es consecuencia del comportamiento comisivo u omisivo del titular de una posición jurídica subjetiva favorable, que se reputa por el ordenamiento jurídico como incompatible con tal posición, determinando su pérdida, con prescindencia del elemento tiempo.

Así, según lo expuesto, dogmáticamente la caducidad administrativa no siempre posee naturaleza sancionatoria ${ }^{53}$. Desde la Teoría General del Derecho, la caducidad administrativa solo debe considerarse como sancionatoria cuando sea la consecuencia jurídica establecida en caso de incumplimiento de un mandato legal, es decir, de un imperativo dispuesto expresamente por la ley ${ }^{54}$, lo que es relevante, dado que en tales supuestos la revocación del acto deberá seguir los cauces del respectivo procedimiento sancionatorio. En los casos de incumplimiento de exigencias impuestas en un acto administrativo en virtud de facultades expresamente contempladas por el ordenamiento jurídico, la caducidad no posee en rigor naturaleza sancionatoria, dado que dichas exigencias no son sino cláusulas o elementos accesorios (i.e., no esenciales) del acto administrativo (condición, modo y plazo), y en tanto tal, quedan sometidos a su régimen ${ }^{55}$.

52 BATÀ, et al. (2008) pp. 393-397; BUFFONI (2014) pp. 243-244.

53 Gallego (1996) pp. 24-26.

54 Y en tal supuesto, algún sector doctrinal, siguiendo a BERMúdEZ (2014) pp. 173-174, considera que estaremos ante lo que doctrinalmente se denomina como "revocación-sanción", sin perjuicio de que en ocasiones el ordenamiento jurídico confunda las instituciones, llamando caducidad lo que en realidad constituye un supuesto de revocación-sanción. Así puede verse en la Ley No20.417, de 2010, que recoge de manera clara la figura de la revocación-sanción, al señalar en su artículo $38^{\circ}$ que "Las infracciones cuyo conocimiento compete a la Superintendencia, podrán ser objeto de las siguientes sanciones: [...] d) Revocación de la Resolución de Calificación Ambiental" [la negrita es nuestra]. Sin embargo, en la doctrina italiana, Lupo (2013) p. 173, alude precisamente a que existe una peligrosa confusión entre revocación y caducidad, pese a la clara distinción entre ambas: esta se limita a extinguir una relación jurídica, sin importar un reexamen del acto, cuya validez se mantiene incuestionada. Ello, dado que la caducidad afecta la eficacia del acto, no su validez, como lo destacan Gallego (1996) p. 87, y Rodríguez (1994) pp. 346-347.

55 En este sentido se sostiene que “(...) ante el incumplimiento de la condiciones (sic) de una autorización o licencia, y pese a que per se dicho incumplimiento pueda llegar a constituir una infracción, la revocación, [...] no es ni puede ser tal sanción. Más bien y en los supuestos de incumplimiento de condiciones estamos en presencia de un claro ejemplo de caducidad por la ineficacia, de forma sobrevenida, de la que adolece el acto administrativo para continuar amparando una actividad o el ejercicio de un derecho que incumple las condiciones que inicialmente se determinaron en su otorgamiento. El acto administrativo, en esos casos, es ineficaz o incluso inválido de forma sobrevenida, ha caducado en sus efectos y, por tanto, procede revocarlo, entendiendo realmente dicho concepto cuando así es empleado por el legislador como la eliminación o extinción de dicho acto administrativo por no resultar adecuado a partir de ese momento para habilitar una actividad o el ejercicio de un derecho. Esto resulta precisamente porque esas condiciones han variado, de forma voluntaria por el par- 
Con fecha 26 de enero del año 2010 se publicó la Ley $N^{\circ} 20.417$, efectuando importantes modificaciones a la LBMA, entre las cuales está la inclusión de un nuevo artículo 25 ter, que consagró la institución de la caducidad de la RCA. Su ratio radica en que, bajo el esquema original de la LBMA, una actividad amparada por una RCA podía ser ejecutada 8, 10 o 12 años después de su calificación ambiental, ya que la ley no contemplaba condición ni plazo alguno para que el titular del proyecto iniciare las obras. Dicha situación no era deseable, dado que en términos ambientales, una RCA aprobada en un año determinado, lo fue bajo condiciones medioambientales específicas y con un ecosistema de características determinadas, que pueden verse afectadas por variaciones importantes producto de la dinámica de los ecosistemas y de la intervención humana en un lapso relativamente breve $^{56}$. Desarrollando la regulación legal, el artículo $73^{\circ}$ del D.S. $\mathrm{N}^{\circ} 40$, de 2012, del Ministerio de Medio Ambiente, que aprobó el nuevo Reglamento del Sistema de Evaluación de Impacto Ambiental (RSEIA), reglamentó el artículo 25 ter de la LBMA en los siguientes términos:

"La resolución que califique favorablemente un proyecto o actividad caducará cuando hubieren transcurrido más de cinco años sin que se haya iniciado la ejecución del proyecto o actividad autorizada, contados desde su notificación.

Corresponderá a la Superintendencia constatar lo anterior y requerir al Servicio que declare dicha caducidad.

Se entenderá que se ha dado inicio a la ejecución del proyecto o actividad, cuando se realice la ejecución de gestiones, actos u obras, de modo sistemático, ininterrumpido y permanente destinado al desarrollo de la etapa de construcción del proyecto o actividad.

En caso que la Resolución de Calificación Ambiental se pronuncie exclusivamente sobre la fase de cierre de un proyecto o actividad, se entenderá que se ha dado inicio a su ejecución cuando haya comenzado la ejecución del proyecto o actividad de cierre.

El titular deberá informar a la Superintendencia la realización de la gestión, acto o faena mínima que dé cuenta del inicio de la ejecución de obras”.

A su vez, el artículo 16 del RSEIA consagró, en relación el artículo 25 ter de la LBMA, el deber de indicar en el Estudio o Declaración de Impacto Ambiental respectivo la gestión, acto o faena mínima que, según la naturaleza y tipología del proyecto o actividad, dé cuenta del inicio de su ejecución de modo sistemático y permanente, considerándose dicha gestión, acto o faena mínima como inicio de la ejecución del proyecto para efectos del citado artículo 25 ter.

Por su parte, el artículo $4^{\circ}$ Transitorio del RSEIA también se refirió a la caducidad de la RCA, sentando las siguientes reglas de orden temporal:

ticular, a raíz del incumplimiento en el que el mismo incurre. Todo esto, [...], sin perjuicio de que el incumplimiento de las condiciones estipuladas en el acto administrativo provoque, además, la reacción de la Administración imponiendo igualmente la oportuna sanción administrativa, pero que en ningún caso puede confundirse con la medida revocatoria en sí. Por tanto, ante un mismo supuesto de incumplimiento de las condiciones de un acto administrativo podremos observar una doble consecuencia: la caducidad -que no revocación-, y la imposición en su caso de la sanción correspondiente. Ambas se erigen como dos consecuencias jurídicas que no se excluyen de modo mutuo al no ser la primera de ellas, cierta y propiamente, una sanción administrativa...”. Fortes (2006b) p. 166. Asimismo, vid. Gordillo (2004) p. XIII-18.

56 Historia de la Ley No 20.417 (versión digital) p. 712. 
(a) Tratándose de proyectos o actividades calificados favorablemente con anterioridad al 26 de enero de 2010 (fecha de publicación de la Ley No20.417 de 2010) y que no se hubiesen ejecutado, se deberá acreditar ante el SEA, antes del 26 de enero de 2015 (es decir, dentro de un plazo de 5 años), las gestiones, actos o faenas mínimas que permitan constatar el inicio de la ejecución del mismo, y;

(b) Tratándose de proyectos o actividades calificados con posterioridad al 26 de enero de 2010 y con anterioridad a la entrada en vigencia del RSEIA, que no se hubiesen ejecutado, deberán acreditar las gestiones, actos o faenas mínimas que permitan constatar el inicio de la ejecución del mismo, antes de transcurridos cinco años contados desde la notificación de la RCA.

Finalmente, teniendo en consideración las normas expuestas, el Ord. No142034/2014, del SEA, que Imparte Instrucciones sobre la caducidad de la RCA, definió la caducidad en materia ambiental como:

“(...) la extinción del acto administrativo terminal (RCA) que pone fin al procedimiento de evaluación de una Declaración de Impacto Ambiental (DIA) o de un Estudio de Impacto Ambiental (EIA), como consecuencia del incumplimiento de la condición contemplada en la ley, la que consiste en el inicio de la ejecución del proyecto dentro del plazo legal establecido en el artículo 25 ter de la Ley No 19.300”.

Dicha definición es relevante dado que aporta luces respecto a los contornos de la caducidad ambiental, a saber: (i) es una caducidad sustantiva, por cuanto afecta derechos y acciones; (ii) en tanto tal, constituye una causal de extinción de un acto administrativo; (iii) se fundamenta en el incumplimiento de una condición legal de naturaleza resolutoria, esto es, una conditio iuris, dentro de determinado plazo también legalmente establecido.

\section{d) AnÁlisis del RÉGimen legal de CADUCidAd de las RCA}

El adecuado análisis de la caducidad en sede ambiental requiere precisar los elementos de carácter legal que delimitan el régimen jurídico de dicha institución, y que, en tanto tales, operan como límite a la potestad reglamentaria, de forma que la regulación que el RSEIA realiza en relación a la caducidad no puede exceder sus márgenes. De la LBMA se desprende que la caducidad ambiental se caracteriza por los siguientes elementos:

(1) Transcurso del plazo de 5 años, el cual se computa desde la notificación de la respectiva $\mathbf{R C A}^{57}$. Por tanto, la operatoria de la caducidad exige el transcurso de un plazo de 5 años, cuyos dies a quo y dies ad quem se encuentran expresa y legalmente establecidos.

(2) La hipótesis normativa gatillante es la falta de inicio de la ejecución del proyecto o actividad autorizada, es decir, una inactividad del administrado, encargando al RSEIA

\footnotetext{
57 Durante la tramitación parlamentaria de la ley se planteó la posibilidad de que el referido plazo de caducidad se computase desde que la RCA quedara ejecutoriada, y no desde su notificación, ya que podían existir reclamaciones o apelaciones que retrasaran el inicio del proyecto, reduciendo consecuentemente el plazo de caducidad. Al respecto, la Ministra de Medio Ambiente sostuvo que el recurso de reclamación no suspende la RCA, de manera que el titular puede dar inicio a las obras mientras la reclamación se encuentra pendiente, aseverando que si la resolución del recurso tarda un año, el titular contará con ese año para el inicio de las obras. Vid. la Historia de la Ley No 20.417 (versión digital) p. 1564.
} 
definir cuáles son las gestiones, actos o faenas mínimas que, según el tipo de proyecto o actividad, permitirán constatar el inicio de la ejecución del mismo ${ }^{58}$.

(3) La caducidad no opera ope legis, sino que debe ser declarada por la autoridad administrativa, en este caso, el SEA, previa solicitud de la SMA.

(4) La caducidad se detona con ocasión del incumplimiento de ciertas obligaciones legales, de entre las cuales destaca el inicio de la ejecución del proyecto ambientalmente autorizado.

(5) La ley no contempla normas transitorias especiales sobre la materia. La Ley No 20.417 de 2010 no estableció normas de vigencia diferida para las modificaciones efectuadas a la LBMA en materia de caducidad, y, por ende, sus disposiciones rigen desde su publicación el día 26 de enero de 2010, salvo en materia de fiscalización, que sí contempló una norma especial ${ }^{59}$. Por tanto, atendido que la Ley No 20.417 de 2010 puede considerarse como una norma de orden público ${ }^{60}$, la misma rige in actum, salvo las excepciones expresamente contempladas en dicha ley ${ }^{61}$.

\section{e) Naturaleza de la caducidad de la RCA}

Visto el régimen legal que rige la caducidad de la RCA, cabe dilucidar si esta es calificable como una sanción administrativa o si se trata de un supuesto de caducidad por incumplimiento de las modalidades del acto administrativo.

En nuestra doctrina ${ }^{62}$, un sector ha sostenido que la caducidad dispuesta en el artículo 25 ter de la LBMA es un supuesto de caducidad general, mientras que la caducidad a que alude el artículo 3 letra l) de la Ley Orgánica de la SMA sería un supuesto de caducidad-sanción. Esta posición además ha sido afirmada en la mesa de trabajo de la Comisión Asesora Presidencial para la Evaluación del Sistema de Evaluación de Impacto Ambiental, en la cual la caducidad es una de las figuras jurídicas sometidas a revisión ${ }^{63}$. Para otro sec-

\footnotetext{
58 En este sentido, el ámbito de la delegación reglamentaria se encuentra acotado precisamente a dicho objeto, sin perjuicio de la potestad reglamentaria autónoma que pueda ser ejercida. Sin embargo, pese a ello, ha sido la autoridad administrativa la cual, directamente, ha venido a regular esta materia por medio de su Ord. No142034/2014, de 21 de noviembre.

59 El artículo $9^{\circ}$ transitorio de la ley dispone que "Las normas establecidas en los Títulos II, salvo el párrafo $3^{\circ}$, y III del Artículo Segundo de la presente ley, que crean la Superintendencia del Medio Ambiente, entrarán en vigencia el mismo día que comience su funcionamiento el Tribunal Ambiental”. Al respecto, vid. el Oficio Ordinario No100292 de 25 de enero de 2010, de la Ministra Presidenta y del Director Ejecutivo de CONAMA, que Establece Criterios para la Aplicación de la Ley No20.417, según el cual el artículo 25 ter responde a un supuesto de "vigencia indirecta expresa", según el cual una modificación dependerá, para su entrada en vigencia, de la dictación del reglamento, cuando la ley requiera expresamente su dictación para regular una materia, en circunstancias que sin tal regulación la norma legal resulta inoperante.

60 Entendidas como aquellas normas que “(...) para los supuestos que consideran, imponen necesariamente su propia regulación, sin permitir a los particulares prescindir de ella y establecer otra prescripción diversa. La situación o relación forzosamente debe ser regulada por esa norma...”. Vid. AlesSANDRI (1998) p. 46.

${ }_{61}$ Al respecto vid. los dictámenes $\mathrm{N}^{\circ}$ s 33.078/2010, y 56.794/2004, ambos de la CGR.

62 Herrera y Ruiz-Tagle (2014) p. 177.

63 <http://comision-seia.mma.gob.cl/wp-content/uploads/2015/04/Reunion-Ext-1-mesa-4_-Caducidad.Rev-0.pdf> [fecha de visita: 5/10/2015].
} 
tor $^{64}$, la caducidad de la RCA constituye un supuesto de revocación-sanción, en tanto que extinción del acto administrativo por incumplimiento de obligaciones del destinatario o regulado por el acto.

Por su parte, si bien ni la LBMA ni la Ley No 20.417 de 2010 lo señalan expresamente, la naturaleza sancionatoria de la caducidad en la normativa ambiental fue sostenida durante la tramitación parlamentaria de la citada ley, según consta en la historia de su tramitación legislativa. En esta, la Ministra de Medio Ambiente sostuvo ${ }^{65}$ :

“(...) la caducidad es una sanción aplicable a un inversionista negligente que no ejecuta la actividad o el proyecto contando con una Resolución de Calificación Ambiental, y que los demás elementos que se han señalado como obtener una RCA con información e instrumentos falsos, y otros, deben ser conocidos y resueltos en las instancias jurisdiccionales que correspondan..." [las negritas son nuestras].

De acuerdo con los desarrollos previos, en rigor, el supuesto del artículo 25 ter de la LBMA debe considerarse como uno de caducidad-sanción, dado que la caducidad se dispone como la consecuencia jurídica para el supuesto de incumplimiento de una exigencia de orden legal (inicio de ejecución dentro de plazo), tratándose así de una sanción dispuesta por no cumplimiento del ordenamiento jurídico. En efecto, aun cuando la caducidad se funda en una inacción del titular de la RCA, lo cierto es que la extinción en que consiste la caducidad encuentra su fundamento directo en la ley, dado que es esta la que exige el inicio de la ejecución del proyecto o actividad dentro de cierto plazo, y es esta la que, asimismo, establece la extinción como sanción a dicho incumplimiento. Así, la referida caducidad sanciona el incumplimiento de una exigencia legal.

La consideración precedente, por cierto, no es una novedad en nuestro ordenamiento jurídico. Cabe recordar que el artículo 1.4.17. de la Ordenanza General de Urbanismo y Construcciones, facultada por el artículo 120 de la Ley General de Urbanismo y Construcciones, dispone que el permiso de edificación caducará automáticamente a los 3 años de concedido si no se hubieren iniciado las obras correspondientes o si estas hubieren permanecido paralizadas durante el mismo lapso. Respecto a dicha disposición, el Ministerio de Vivienda y Urbanismo, por medio de su División de Desarrollo Urbano, ha señalado que ella “(...) sanciona la omisión en que incurre el titular del respectivo permiso al no haber iniciado las obras correspondientes o al mantenerlas paralizadas en el lapso de tres años fijados...."66. Como se puede apreciar, para dicho organismo la referida caducidad posee naturaleza sancionatoria.

\footnotetext{
64 Cordero (2015) p. 315.

65 Historia de la Ley No 20.417 (versión digital) p. 1565.

66 Circular Ord. No 0015, de 10 de enero de 2008.
} 


\section{INFRACCIONES EN QUE INCURRE EL RSEIA}

a)

POSICIÓN

Parece ser el entendimiento del RSEIA que la aplicación de la caducidad a las indicadas RCA es ajustada a Derecho en la medida que dicha aplicación opera desde la fecha de vigencia de las modificaciones introducidas en la LBMA por la Ley No20.417 de 2010 (esto es, el 26 de enero de 2010).

Sin embargo, con dicha regulación, el régimen transitorio contemplado por el RSEIA rebasa la regulación que la LBMA establece para la caducidad de las RCA, e incluso incurre en una vulneración del principio de reserva de ley. En efecto, según se expondrá, la señalada regulación reglamentaria ha hecho aplicable a los proyectos con una RCA vigente al momento de entrada en vigencia de las modificaciones efectuadas por la Ley No20.417, una nueva causal de extinción del acto administrativo autorizatorio, previamente inexistente, afectando de dicha manera las situaciones jurídicas consolidadas tras la emisión de las respectivas RCA. Lo anterior fue efectuado no solo careciendo de respaldo legal sino que en abierta contradicción con el texto normativo vigente y con la reserva legal existente en la materia. En efecto, según se expondrá a continuación, la regulación contenida en el RSEIA contraviene el régimen que legalmente ha establecido la LBMA en relación con la caducidad de la RCA. Dicha contravención se aprecia en los siguientes órdenes de materias: (i) respecto al dies a quo para computar el plazo de caducidad; (ii) en relación al régimen intertemporal dispuesto en la ley; (iii) respecto del carácter sancionatorio de la caducidad; y (iv) respecto a la irretroactividad de los actos administrativos. Seguidamente se desarrollan las ilegalidades denunciadas.

\section{b) ILEGALIDADES ADVERTIDAS}

\section{(b.i) El RSEIA establece un dies a quo diverso al legalmente dispuesto}

Como hemos expuesto, el artículo 25 ter de la LBMA dispone en forma expresa que el plazo de caducidad se computa desde la fecha de notificación de la RCA, sin contemplar otro hito diverso a partir del cual contabilizar dicho plazo. Así, la caducidad, como causal de extinción del acto administrativo que es la RCA quedó legalmente configurada entre otros elementos, por un dies a quo consistente en la notificación de la RCA. Lo anterior es relevante dado que, siendo ello así, queda vedado a la potestad reglamentaria alterar dicho elemento.

No obstante, el RSEIA ha creado un hito diverso a la notificación, al establecer que, tratándose de RCA otorgadas con anterioridad al 26 de enero de 2010, el plazo de caducidad comenzará a computarse a partir de dicha fecha. Dicha alteración reglamentaria del régimen legal de la caducidad implica una vulneración al principio de jerarquía normativa ${ }^{67}$,

\footnotetext{
67 Al respecto, por dictamen No38.004, de 2005, la CGR señaló: “(...) es del caso recordar, que el ordenamiento jurídico nacional está constituido por un sistema jerarquizado de normas que se encuentran subordinadas entre sí. En este sentido, es dable anotar que el principio de jerarquía normativa es obligatorio para todos los Órganos del Estado, cualquiera fuere su naturaleza o actividad, debiendo en la interpretación o aplicación
} 
en tanto que se contraviene en forma directa el tenor literal de la ley. Si bien se comprende que el RSEIA pretendió no dotar de efecto retroactivo a la regulación de la caducidad dispuesta por la Ley No20.417, estableciendo como fecha de inicio del cómputo del plazo la de entrada en vigor de la ley, lo cierto es que al hacerlo se separó de la regulación legal de la caducidad, convirtiéndose así en un reglamento contra legem ${ }^{68}$.

A mayor abundamiento, la regulación del RSEIA conlleva la creación reglamentaria de una nueva causal de caducidad, diversa a la legalmente prevista, y por ende, de una causal de extinción de la RCA. Ello implica una contravención a la reserva legal contemplada en el artículo 63 No18 de la Constitución Política, que indica que solo son materias de ley las que fijen las bases de los procedimientos que rigen los actos de la administración pública, el cual debe vincularse con el artículo $7^{\circ}$ de la Constitución, según el cual los órganos del Estado actúan válidamente en la forma que prescriba la ley ${ }^{69}$. Como se puede apreciar en la LPA, lo relativo a las causales de extinción de los actos administrativos se encuentra comprendido en la reserva de ley, en el entendido que los procedimientos administrativos concluyen por medio de un acto terminal que da origen a un acto administrativo, el cual puede a su vez extinguirse de acuerdo con las causales y procedimientos previstos al efecto. Y siendo ello así, queda vedado a la potestad reglamentaria regular tales materias.

Y finalmente, lo expuesto implica asimismo una contravención del principio de seguridad jurídica, en tanto que se altera el status legalmente establecido creando una causal de extinción del acto administrativo, no prevista. Como ha señalado la doctrina:

del ordenamiento jurídico, ajustarse al principio de juridicidad y, dentro de este, a la jerarquía establecida a partir del orden impuesto por las normas de mayor rango...”.

68 Ni siquiera el recurso a la potestad reglamentaria autónoma es suficiente para justificar la desviación reglamentaria del texto legal, ya que como ha destacado la doctrina dicho reglamentos “(...) son aquellos que se dictan praeter legem, es decir, sin una ley previa a cuya ejecución se atiende. No son, claro está, reglamentos contra legem, prohibidos por el principio de jerarquía normativa, sino reglamentos que no tienen como finalidad el desarrollo de normas legales previas en la materia de que se trate, que no aparecen como complementarios de una ley, sino que regulan materias de las que no se ha ocupado el legislador o de las que se ha ocupado de manera fragmentaria...”. Dе Отто (1988) р. 218.

${ }^{69} \mathrm{Al}$ respecto, el TC ha sostenido: “(...) Que los artículos impugnados, como todos los que regulan la actividad sancionadora de la Administración, están sujetos al principio de legalidad; desde luego, en virtud de los preceptos básicos contenidos en el Capítulo I de la Constitución, particularmente en sus artículos 6 y 7 que establecen la sujeción de toda actividad de los órganos del Estado al ordenamiento jurídico y muy especialmente, en cuanto los dos primeros incisos del artículo $7^{\circ}$ de la Constitución, los sujetan a la Carta Fundamental y a la ley, al disponer que los órganos del Estado solo actúan válidamente si lo hacen dentro de su competencia y en la forma prescrita en la ley y que ninguna magistratura puede atribuirse, ni aún a pretexto de circunstancias extraordinarias, otra autoridad que la que se le haya conferido en virtud de la Constitución o las leyes. Complementa este principio básico de exigencia de legalidad de los actos de la administración el precepto contenido en el numeral 18 del artículo 63, en cuanto exige que sean de jerarquía legal las normas que fijen las bases de los procedimientos que rigen los actos de la administración pública y el inciso cuarto del artículo 65 en cuanto reserva al Presidente de la República la iniciativa exclusiva de las leyes que crean nuevos servicios públicos...”. (COMPAÑÍA ELÉCTRICA SAN ISIDRO S. A. Y OTRAS CON SUPERINTENDENCIA DE ELECTRICIDAD Y COMBUSTIBLES (2006), Ley No 18.410, Orgánica de la Superintendencia de Electricidad y Combustibles, Rol 479-06; IBEROAMERICANA DE ENERGÍA IBENER S. A. CON SUPERINTENDENCIA DE ELECTRICIDAD Y COMBUSTIBLES (2006), Ley No 18.410, Orgánica de la Superintendencia de Electricidad y Combustibles, Rol 480-06. 
“(...) [e]l factor de destrucción de la capacidad productiva del acto debe, necesariamente, encontrarse previsto en el sistema positivo vigente. Su imprevisión atentaría en contra de la seguridad jurídica. Al mismo tiempo, la "predeterminación de los medios de extinción de los actos de la administración” por las normas superiores del sistema jurídico, afianza la vinculación de la autoridad a sus propias manifestaciones positivas desde el momento que no podrá dejar de cumplirlas, ni podrá tampoco modificarlas o derogarlas sino en virtud de una expresa habilitación legal..." [las negritas son nuestras] (MADARIAGA, 1993, p. 99)

\section{(b.ii) El RSEIA establece un régimen intertemporal diverso al legalmente dispuesto}

Según hemos indicado, la Ley No20.417 no contempló vacatio legis alguna en relación al régimen de caducidad implementado, rigiendo por tanto in actum. Ello conlleva que sus disposiciones (salvo las excepciones legales) han de ejecutarse a partir de la entrada en vigor de la ley y en los estrictos términos previstos en ella. Según se puede desprender de la historia legislativa de la Ley No20.417, esta no se planteó la aplicación de las reglas sobre caducidad a las RCA vigentes, sino que simplemente implementó un régimen con eficacia hacia el futuro.

Sin embargo, el RSEIA implementó un régimen para regular las situaciones intertemporales o transitorias surgidas con ocasión de la entrada en vigor de la Ley No20.417. En la especie, reguló la situación de las RCA dictadas y notificadas con anterioridad a la entrada en vigencia de la Ley No20.417, creando un régimen que contraviene las disposiciones permanentes de la citada ley.

\section{(b.iii) El RSEIA obvia la naturaleza sancionatoria de la caducidad}

Atendido el tenor de las normas citadas y la historia legislativa de la nueva institucionalidad ambiental, la caducidad de la RCA posee una clara naturaleza sancionatoria. Como se expuso, la caducidad se dispone en la ley como una sanción en aquellos supuestos en los cuales el titular de la RCA no da cumplimiento al plazo de 5 años para dar inicio a la ejecución del proyecto o actividad. Siendo ello así, dicha caducidad debe ser interpretada de manera estricta ${ }^{70}$, lo que implica su aplicación en los exactos términos legales previstos en la norma. En virtud de lo expuesto, el cómputo de los 5 años debería efectuarse necesariamente desde la fecha de notificación de la RCA, por expreso mandato legal.

\section{(b.iv) El RSEIA vulnera la LPA en materia de irretroactividad de los actos administrativos}

La retroactividad se define de forma general como la “(...) producción de efectos con relación a situaciones o casos producidos con anterioridad a la entrada en vigor de la norma o a la emanación del correspondiente acto...”11, de lo cual se desprende que la cuestión de la retroactividad suele estar relacionada con la de las situaciones de transitoriedad,

$70 \mathrm{Al}$ respecto, vid. el dictamen No 761, de 1994, de la CGR.

71 Canos (2004) p. 171; Belando (2008) p. 28. 
es decir, de paso de una norma a otra ${ }^{72}$. El elemento característico de la retroactividad en los ordenamientos jurídicos contemporáneos es la tendencia más o menos generalizada a su prohibición, de lo cual se ha derivado una regla general de irretroactividad de las normas, la que para algunos incluso constituye un principio general del Derecho ${ }^{73}$.

Dicha regla tiene su reflejo en el ámbito administrativo, en el cual también existe la tendencia a su limitación. El artículo $52^{\circ}$ de la LPA dispone que "Los actos administrativos no tendrán efecto retroactivo, salvo cuando produzcan consecuencias favorables para los interesados y no lesionen derechos de terceros", declaración la cual tiene como fundamento general la garantía de la seguridad jurídica ${ }^{74}$, en tanto tiende a proteger al ciudadano ante actuaciones de la Administración que puedan afectar negativamente sus situaciones jurídi$\mathrm{cas}^{75}$. Sin perjuicio de ello, la doctrina cita también otros fundamentos, entre los que merecen ser destacados el principio de legalidad o el respeto de los derechos adquiridos ${ }^{76}$, si bien se sostiene que, en definitiva, se trata de "nuevas perspectivas del principio de seguridad jurídica"77.

De forma similar a lo que sucede con la prohibición de retroactividad dispuesta en el artículo $9^{\circ}$ del Código Civil, la cual se considera como un mandato para el juez, y que en tanto tal no impide al legislador dictar leyes retroactivas en el marco de las limitaciones que al efecto se desprenden de la Constitución Política, en materia administrativa la señalada prohibición de irretroactividad constituye un mandato para el Estado/Administración, pero no para el Estado/legislador, el cual no se ve impedido de dictar leyes que consagren la retroactividad en ciertos casos, siempre respetando el marco que al efecto se desprende de la Constitución.

De la mera lectura del artículo $52^{\circ}$ de la LPA se desprende cuáles son los límites de la retroactividad de los actos administrativos, los que son copulativos ${ }^{78}$ atendido el uso de la conjunción "y". Dichos límites son: (i) la no producción de consecuencias favorables para los interesados, lo cual ha de vincularse con aquella clasificación de los actos administrativos que distingue entre actos de gravamen y actos favorables, entendiendo por estos los que amplían la esfera jurídica del administrado, crean una situación jurídica favorable, liberan de una obligación, o crean facultades, entre otras consecuencias ${ }^{79}, y$, con el concepto de "interesados" contenido en el artículo $21^{\circ}$ de la LPA, cuyo número 2 solapa con el concepto de "terceros"; y (ii) la no lesión de derechos de terceros, lo cual implica que quedan

\footnotetext{
72 Verdera (2006) pp. 48-49.

73 Así, vid. el dictamen $N^{\circ} 62.000$, de 1969, de la CGR; y lo señalado por BELANDo (2008) p. 40. Si bien la posibilidad de que dicho mandato pueda ser desconocido por el legislador, precisamente por medio de la dictación de normas retroactivas, mueve a la autora a negar tal calificación como Principio General del Derecho.

74 Como lo reconoce expresamente el Dictamen No40.245, de 2015 de la CGR.

75 García de Enterría y Fernández (2008) pp. 594-595; Belando Garín (2008) pp. 41-42; García-Trevijano (1986) p. 341; López Menudo (1982) pp. 38-39; Madariaga (1993) p. 166; Verdera Izquierdo (2006) pp. 31-42; SuÁrez Collía (1994) pp. 41-51.

76 García de Enterría y Fernández (2008) pp. 594-595; Suárez Collía (1994) pp. 51-62; Belando Garín (2008) p. 42; López Menudo (1982) pp. 37-38.

77 Belando Garín (2008) p. 43.

78 Así el dictamen No 34.810, de 2006, de la CGR, y en la doctrina, Moraga Klenner (2010) p. 251.

79 García-Trevijano (1986) p. 220.
} 
excluidas del ámbito de la irretroactividad las lesiones a meras expectativas. Así, el citado precepto habilita a las autoridades, solo de un modo excepcional ${ }^{80}$, para dictar actos que puedan tener efectos retroactivos en la medida que concurran los supuestos y requisitos que la norma exige, por lo que tal excepción al principio de irretroactividad, atendida su naturaleza, debe ser interpretada y aplicada restrictivamente.

Pese a lo expuesto, el RSEIA se ha dictado omitiendo la referida limitación. En efecto, el RSEIA, que entró en vigencia el día 24 de diciembre de 2013, dispuso que las RCA dictadas con anterioridad a la fecha de vigencia de la Ley No 20.417, de 2010, esto es, el 26 de enero de 2010, se encuentran igualmente sujetas al régimen de caducidad establecido por dicha ley. Al obrar de dicha forma, el RSEIA ha dotado de eficacia retroactiva a sus disposiciones, al abarcar situaciones jurídicas en desarrollo con anterioridad a la fecha de vigencia del referido reglamento, vulnerando así la exigencia de que el acto en cuestión debe producir consecuencias favorables a favor del interesado para poder poseer eficacia retroactiva.

\section{CONCLUSIONES}

La Ley No 20.417 de 2010 estableció una nueva causal de extinción del acto administrativo que es la RCA sin regular la situación de aquellas que estuvieran vigentes al momento de entrada en vigor de dicha ley. Sin embargo, el RSEIA, al desarrollar las disposiciones legales sobre la caducidad, se separó del legítimo ámbito del desarrollo reglamentario, al establecer un dies a quo para el cómputo de la caducidad, diverso al contemplado en la ley. Al obrar de dicha forma, el RSEIA no solo contravino el tenor de la ley (principio de jerarquía normativa) sino que además incurrió en vulneración de la reserva de ley a que están sometidos los modos de extinción de los actos administrativos, al crear una causal de caducidad nueva cuyo dies a quo es el día 26 de enero de 2010 y no el de notificación de las RCA, establecido por la ley. Asimismo, la referida creación omite la naturaleza sancionatoria de la caducidad establecida en el artículo 25 ter de la LBMA, al extender el radio de acción de esta a supuestos no contemplados por la ley, como son las RCA vigentes al 26 de enero de 2010. Y finalmente, el RSEIA vulneró la prohibición de retroactividad de los actos administrativos, al pretender incluir dentro del radio de eficacia de la caducidad situaciones jurídicas en desarrollo en una fecha anterior a la entrada en vigencia del propio RSEIA, esto es, el 24 de diciembre de 2013.

Así, en rigor, a fin de atenerse a la legalidad, el RSEIA debería haber dispuesto que todas las RCA notificadas a partir de la fecha de entrada en vigor de la Ley No20.417 estarían sometidas al plazo de caducidad, computado precisamente a partir de la correspondiente fecha de notificación.

80 Vid. los dictámenes Nos 34.810, de 2006, y 42.118, de 2009, ambos de la CGR. 


\section{BIBLIOGRAFÍA CITADA}

Alcalde Rodríguez, Enrique (2013): La responsabilidad de los directores de sociedades anónimas. Responsabilidad civil y penal administrativa (Santiago, Ediciones $\mathrm{UC})$.

Alessandri Besa, Arturo (1949): La nulidad y la rescisión en el Derecho Civil chileno (Titulo XX del Libro IV del Código Civil) (Santiago, Ediar Editores, Tomo I).

Alessandri Rodríguez, Arturo, et al. (1998): Tratado de Derecho Civil: Partes Preliminar y General, Tomo I (Editorial Jurídica de Chile, Santiago).

Aróstica Maldonado, Iván (1991): "Un lustro de sanciones administrativas (19881992)", en Revista de Derecho Público, Vol.50; pp. 173-195.

Astorga Jorquera, Eduardo (2007): Derecho Ambiental Chileno (Santiago, LexisNexis).

BATÀ, Antonella, et al. (2008): La prescrizione e la decadenza, $3^{\mathrm{a}}$ ed. (Roma, Wolters Kluwer, tercera edición).

Belando Garín, Beatriz (2008): La eficacia retroactiva de los actos administrativos (Madrid, Thomson-Civitas).

Bermúdez Soto, Jorge (2014): Derecho Administrativo General, 3a ed. actualizada (Santiago, Legal Publishing Thomson Reuters, tercera edición).

Bermúdez Soto, Jorge (2013): "Fundamento y límites de la potestad sancionadora administrativa en materia ambiental”, en Revista de Derecho de la Pontificia Universidad Católica de Valparaíso, XL; pp. 421-447.

Bermúdez Soto, Jorge (1998): "Elementos para definir las sanciones administrativas", en Revista Chilena de Derecho, Número Especial; pp. 323-334.

Bocanegra Sierra, Raúl (2002): Lecciones sobre el acto administrativo (Madrid, Civitas).

Buffoni, Marta (2014): "La decadenza", en: Cassano, Giuseppe [ed.], Prescrizione e decadenza come farle valere nel processo (Santarcangelo, Maggioli Editore); pp. 235-300.

Caballero Sánchez, Rafael (1999): "Nacimiento y evolución del instituto de la caducidad en el Derecho Administrativo", en Revista Vasca de Administración Pública, Vol.55; pp. 9-69.

Canos Campos, Tomás (2004): La invalidez sobrevenida de los actos administrativos (Madrid, Civitas).

Cassagne, Juan Carlos (2002): Derecho Administrativo (Buenos Aires, LexisNexis, Tomo II, $7^{\text {a }}$ edición).

Cea Egaña, José Luis (1991): "Variación del estatuto del dominio sobre concesiones de radiodifusión televisiva", en Revista Chilena de Derecho, Vol. 18, No 3; pp. 479-495.

Cordero Vega, Luis (2015): Lecciones de Derecho Administrativo, 2a ed. (Thomson Reuters, Chile).

Cordero Vega, Luis (2013): "Interpretación de las Resoluciones de Calificación Ambiental”, en El Mercurio Legal, Jueves 25 de abril.

Cordero Vega, Luis (2011): "El decaimiento del procedimiento administrativo sancionador", en Anuario de Derecho Público (UDP); pp. 243-255.

Dе Отто, Ignacio (1988): Derecho Constitucional. Sistema de fuentes (Ariel, España).

Dromi, José Roberto (2008): Acto Administrativo (Buenos Aires, Ciudad Argentina) 
Fermandois Vöhringer, Arturo (2005): "Invalidación Administrativa y caso Celco: estabilidad o precariedad de los permisos ambientales", en Fermandois, Arturo (ed), Sentencias Destacadas 2005, Una mirada desde la perspectiva de las políticas públicas (Santiago, Libertad y Desarrollo); pp. 9-30.

Fernández, Tomás-Ramón (2006): Manual de Derecho Urbanistico (Madrid, Ed. La Ley, 19a edición). Fernández, Tomás-Ramón (1967): "Inscripciones y autorizaciones industriales”, en Revista de Administración pública, No 52; pp. 422-446.

Fortes Martín, Antonio (2006a): "Aplicación de los instrumentos normativos de tutela ambiental en el sector energético: retos e incertidumbres en las grandes instalaciones de combustión a partir del nuevo escenario ambiental resultante del régimen de prevención y control integrados de la contaminación”, en: VV.AA., Derecho de la Energía (Madrid); pp. 699-764.

Fortes MarTín, Antonio (2006b): "Estudio sobre la revocación de los actos administrativos", en Revista de Derecho (Valdivia), Vol.19, No1; pp. 149-177.

Gallego Anabitarte, Alfredo (1996): "Prólogo" en Velasco Caballero, Francisco (1996): Las cláusulas accesorias del acto administrativo (Madrid, Tecnos); pp. 17-29.

García de Enterría, Eduardo, y Fernández, Tomás-Ramón (2008): Curso de Derecho Administrativo (Madrid, Thomson Civitas, Tomo I, 14a ed).

García de Enterría, Eduardo, y Fernández, Tomás-Ramón (2006): Curso de Derecho Administrativo (Madrid, Thomson Civitas, Tomo II, 10ª ed.).

GarCía NAVAS, Ana (1999): "Sobre la autorización industrial necesaria para la instalación de centrales de producción de energía eléctrica tras la nueva ley del sector eléctrico”, en Revista Jurídica de la Comunidad de Madrid, No 5.

García Pérez, Marta (1997): "La naturaleza jurídica de la autorización y la concesión, a propósito de la utilización del dominio público", en Anuario da Facultade de Dereito da Universidade da Coruña, No 1; pp. 337-352.

García-Trevijano, José (1986): Los actos administrativos (Madrid, Civitas).

Giglioni, Fabio (2008): L’Accesso al mercato nei servizi di interesse generale (Milán, Giuffrè Editore).

GonzÁlez Navarro, Francisco (1964): "La llamada caducidad del procedimiento administrativo", en Revista de Administración Pública, No 45; pp. 191-230.

Gordillo, Agustín (2004): Tratado de derecho administrativo (Buenos Aires, Fundación de Derecho Administrativo, Tomo 3, 8a ed.).

Herrera, Javier, y Ruiz-Tagle, Samuel (2014): "La caducidad de la Resolución de Calificación Ambiental”, en Revista de Derecho, Vol. XXVII, No1; pp. 169-190.

Jara Schnettler, Jaime (2004): La nulidad de Derecho Público ante la doctrina y la jurisprudencia (Santiago, Editorial Libromar).

JellineK, Walter (1908): Der Fehlerhafte Staatsakt und seine Wirkungen: Eine Verwaltungs und Prozessrechtliche Studie (Tübinger, Kessinger Publishing)

Laguna de PAZ, José Carlos (2006): La autorización administrativa (Madrid, Civitas).

Lira Urquieta, Pedro (2009): "Concepto jurídico de caducidad y prescripción extintiva”, en Tavolari, Raúl (ed.), Revista de Derecho y Jurisprudencia (Santiago, Editorial Jurídica, Punto Lex, Thomson Reuters, Tomo II, Edición Bicentenario) pp. 595-624. 
López Menudo, Francisco (1982): El principio de irretroactividad en las normas jurídicol administrativas (Sevilla, Ediciones del Instituto García Oviedo).

Lupo, Antonietta (2013): Premesse per uno studio sulla revoca degli atti amministrativi (Milán, Giuffrè Editore).

Madariaga Gutiérrez, Mónica (1994): "Caducidad de merced provisional de aguas", Revista de Derecho de Aguas, Vol. V; pp. 85-97.

Madariaga Gutiérrez, Mónica (1993): Seguridad jurídica y Administración Pública en el siglo XXI (Santiago, Ed. Jurídica de Chile, 2a edición Actualizada).

Martín Mateo, Ramón (1965): "Silencio positivo y actividad autorizante", Revista de Administración Pública, Vol.48; pp. 205-240.

Martín-Retortillo, Sebastián (1985): Manual de Derecho Administrativo (Madrid, Instituto de Estudios de Administración Local, 9a ed.).

Martín-Retortillo, Sebastián (2007): Instituciones de Derecho Administrativo (Madrid, Thomson-Civitas).

Martín-Retortillo, Sebastián (1957): "Acción administrativa sanitaria: la autorización para la apertura de farmacias”, Revista de Administración Pública, Vol. 24; pp. 117-162.

Maurer, Hartmut (2012): Derecho Administrativo Alemán (traducido por C.H. Beck, México, Universidad Autónoma de México, 16ª edición).

MeILÁn Gil, Juan (1973): "Sobre la determinación conceptual de la autorización y la concesión”, Revista de Administración Pública, Vol.71; pp. 59-99.

Millar Silva, Javier (2008): La potestad invalidatoria en el Derecho chileno, Tesis para optar al grado de Doctor en Derecho (Santiago, Universidad de Chile).

Moraga Klenner, Claudio (2010): Tratado de Derecho Administrativo. La actividad formal de la Administración del Estado (Santiago, LegalPublishing, Tomo VII).

Navarro Beltrán, Enrique (2005): "Notas sobre potestad sancionatoria de la autoridad administrativa y principio de legalidad", Revista de Derecho Público, Vol.67; pp. 118-128.

Nino, Carlos (2003): Introducción al análisis del Derecho (Buenos Aires, Astrea, 2a ed. ampliada y revisada).

MaYer, Otto (1895): Deutsches Verwaltungsrecht (Leipzig, Duncker und Humblot, $1^{\text {a }} \mathrm{Ed}$.)

Parejo Alfonso, Luciano (2008): Lecciones de Derecho Administrativo (Madrid, Tirant lo Blanch, 2a ed).

Piccinini García, Doris (1968): Teoría del decaimiento de los actos administrativos (Santiago, Ed. Jurídica de Chile).

Prieto Sanchís, Luis (2008): Apuntes de Teoría del Derecho (Madrid, Editorial Trotta, $3^{\mathrm{a}} \mathrm{ed}$.).

RANELletTI, Oreste (1894a): “Teoria generale delle autorizzazioni e concessioni amministrative. Parte I: Concetto e natura delle autorizzazioni e concessioni amministrative", Giurisprudenza italiana, Vol. VI; pp. 7-83

Ranelletti, Oreste (1894b) "Teoria generale delle autorizzazioni e concessioni amministrative. Parte II: Capacità e volontà nelle autorizzazioni e concessioni amministrative", Rivista italiana per le scienze giuridiche, Vol. XVII; pp. 3-100 
RANELlETti, Oreste (1895) "Teoria generale delle autorizzazioni e concessioni amministrative. Parte III: Facoltà create dalle autorizzazioni e concessioni amministrative" Rivista italiana per le scienze giuridiche, Vol. XIX; pp. 3-107

Ranelletti, Oreste (1896) "Teoria generale delle autorizzazioni e concessioni amministrative. Parte III: Facoltà create dalle autorizzazioni e concessioni amministrative" Rivista italiana per le scienze giuridiche, Vol. XXI; pp. 77-172

Ranelletti, Oreste (1897) "Teoria generale delle autorizzazioni e concessioni amministrative. Parte III: Facoltà create dalle autorizzazioni e concessioni amministrative" Rivista italiana per le scienze giuridiche, Vol. XXII; pp. 177-277

Rebollo Puig, Manuel, et al. (2010): Derecho Administrativo Sancionador (Valladolid, Lex Nova).

Rodríguez Arana, Jaime (1994): "Reflexiones sobre la caducidad en el Derecho Público”, Revista Aragonesa de Administración Pública, Vol.5; pp. 341-355.

Rodríguez Grez, Pablo (2008): Extinción no convencional de las obligaciones (Santiago, Editorial Jurídica, Volumen 2).

Rojas Calderón, Christian (2007): "Sistema de revisión de los actos administrativos contemplados en la Ley General de Pesca y Acuicultura (a la luz de los estándares de la Ley de Bases de Procedimientos Administrativos)", Revista de Derecho Público, Vol. 69, Tomo II; pp. 117-138.

Ruiz-Tagle Vial, Pablo (1990): Revisión crítica del Derecho (Santiago, Cuadernos Universitarios, Universidad Nacional Andrés Bello).

Santamaría Pastor, Juan Alfonso (2005): Principios de Derecho Administrativo General (Madrid, Iustel, T.II).

Schmidt-Assmann, Eberhard (2003): La teoría general del Derecho Administrativo como sistema (Madrid, Marcial Pons).

Sepúlveda Solar, Doris (2008): Invalidación Sobreviniente de la Resolución de Calificación Ambiental por Modificación de su Presupuesto de Hecho, Memoria de Prueba para optar al grado de licenciado en ciencias jurídicas y sociales (Santiago, Universidad de Chile).

Silva Cimma, Enrique (1995): Derecho Administrativo chileno y comparado. Actos, contratos y bienes (Santiago, Ed. Jurídica de Chile).

Soria, Daniel (2003): "Consideraciones sobre la caducidad como medio de extinción del acto administrativo”, en VV.AA, El Derecho Público a comienzos del siglo XXI. Estudios en homenaje al profesor Allan R. Brewer Carias (Madrid Civitas); pp. 1715-1747.

Soто KLoss, Eduardo (2009): Derecho Administrativo. Temas Fundamentales (Santiago, LegalPublishing).

STOBER, Rolf (1992): Derecho Administrativo Económico (traducción por Ministerio para las Administraciones Públicas, Madrid, Colección Estudios MAP).

SuÁrez Collía, José (1994): El principio de irretroactividad de las normas jurídicas, 2a ed. (Actas, España).

Tardío Pato, José Antonio (2005): "Consideraciones Sobre la Caducidad del Procedimiento Administrativo", Revista de Estudios de la Administración Local y Autonómica, No 298-299; pp. 11-53. 
Ubilla Grandi, Luis (1990): Teoría general de la letra de cambio y del pagaré en la Ley 18.092 (Santiago, Ed. Jurídica).

Valencia Martín, Germán (2009): "Evaluación de impacto ambiental y autorización ambiental integrada”, en: VV.AA, Evaluación de impacto ambiental. Evolución normativo-jurisprudencial, cuestiones procedimentales y aplicación sectorial (Barcelona, Atelier Libros); pp. 69-120.

Velasco Caballero, Francisco (1996): Las cláusulas accesorias del acto administrativo (Madrid, Tecnos).

Verdera IzQUierdo, Beatriz (2006): La irretroactividad: problemática general (Madrid, Dykinson).

Vergara Blanco, Alejandro (2004a): "Notas sobre la caducidad como fuente de extinción de derechos y del decaimiento del procedimiento administrativo", en: VV.AA, Actas XXXIV Jornadas de Derecho Público (Santiago, PUC): pp. 567-572.

Vergara Blanco, Alejandro (2004b): "El nuevo servicio público abierto a la competencia: de la publicatio al libre acceso. Coherencia de las viejas técnicas concesional y autorizacional", Revista de Derecho Administrativo Económico, Vol.12; pp. 33-49.

VIrga, Pietro (2001a): Diritto Amministrativo, I principi 1 (Milán, Giuffrè editore, 6a ed).

- (2001b): Diritto Amministrativo, Atti e ricorsi 2 (Milán, Giuffrè editore, 6ª ed).

\section{NORMAS CITADAS}

Ley No 17.105, del 14 de abril de 1969, que fija texto refundido de la Ley de alcoholes, bebidas alcohólicas y vinagres

Ley No 18.168, del 2 de octubre de 1982, Ley General de Telecomunicaciones

Ley No 18.175, del 28 de octubre de 1982, que fija nuevo texto de Ley de Quiebras

Ley No 18.892, del 23 de diciembre de 1989, Ley General de Pesca y Acuicultura

Ley $N^{o} 19.260$, del 4 de diciembre de 1993, que modifica Ley $\mathrm{N}^{\circ} 17.322$ y Decreto Ley $\mathrm{N}^{\circ} 3.500$, de 1980 y dicta otras normas de carácter previsional

Ley No 19.300, del 9 de marzo de 1994, que aprueba Ley sobre Bases Generales del Medio Ambiente

Ley No 19.542, del 19 de diciembre de 1997, que moderniza el Sector Portuario Estatal

Ley No 19.657, del 7 de enero de 2000, sobre Concesiones de Energía Geotérmica

Ley No 19.880, del 29 de mayo de 2003, que establece Bases de los procedimientos administrativos que rigen los actos de los órganos de la administración del Estado.

Ley No 19.925, del 19 de enero de 2004, Ley sobre Expendio y Consumo de Bebidas Alcohólicas

Ley No 20.417, del 26 de enero de 2010, que crea el Ministerio, el Servicio de Evaluación Ambiental y la Superintendencia del Medio Ambiente

Ley No 20.600, del 28 de junio del 2012, que crea los Tribunales Ambientales

Decreto con Fuerza de Ley No458, de 13 de abril de 1976, Aprueba Nueva Ley General de Urbanismo y Construcciones

Decreto No47, del Ministerio de Vivienda y Urbanismo, de 5 de junio de 1992, Fija Nuevo Texto de la Ordenanza General de Urbanismo y Construcciones 


\section{JURISPRUDENCIA CITADA}

Sociedad Visal Ltda. con Empresa Portuaria de ARica (2006): Tribunal Constitucional, 14 de noviembre de 2006 (rechaza requerimiento de inaplicabilidad), Rol 467-06.

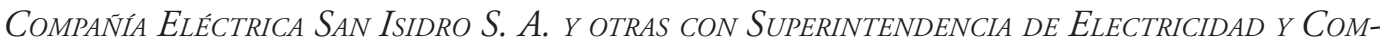
BUSTIBLES (2006): Tribunal Constitucional, 8 de agosto de 2006 (rechaza requerimiento de inaplicabilidad), Rol 479-06.

IBEROAMERICANA DE ENERGÍA IBENER S. A. CON SUPERINTENDENCIA DE ELECTRICIDAd Y COMBUSTIBLES (2006): Tribunal Constitucional, 27 de julio de 2006 (rechaza requerimiento de inaplicabilidad), Rol 480-06.

Llona con Instituto de Normalización PREVISional (2007): Corte Suprema, 28 de noviembre del 2007 (se rechaza, sin costas, el recurso de casación en el fondo deducido por la demandada), Rol No 4101-2007.

Martínez Pita, Guadalupe Inés y otros con Alcalde de la I. Municipalidad de Pucón y el Director del Depto. de Rentas y Patentes Municipales (2008): Corte de Apelaciones de Temuco 18 de marzo del 2008 (se acoge con costas, el recurso deducido en favor de doña Martínez Pita, de don Villamil Amorin, de la sociedad "Luis Cervando Roa y otro" y de la sociedad “Comercial La Maga Limitada), Rol No 1575-2007.

Aguas Andinas S.A., con Comisión Regional del Medio Ambiente de la Región MetropoLITANA (2009): Corte de Apelaciones de Santiago 22 de octubre del 2009 (rechaza recurso de protección), Rol No 6312-2009.

Rosso (2010): Tribunal Constitucional, 16 de noviembre del 2010 (acción de inaplicabilidad), Rol 1413-09- INA.

I. Municipalidad de ARauco Cl Comisión de EVALUación Ambiental de la Región del Bío BÍo (2011); Corte de Apelaciones de Concepción, 17 de junio de 2011 (rechaza el deducido en lo principal del escrito), Rol No 615-2011.

Fiscalía del Medio Ambiente y otros cl Servicio de EValuación Ambiental, Región de AySÉN (2012): Corte de Apelaciones de Coyhaique, 3 de marzo de 2012 (rechaza recurso de protección), Rol No 7-2012.

Fiscalía del Medio Ambiente y otros Cl SerVicio de EVAluación Ambiental, Región de AySÉN (2012): Corte Suprema, 11 de mayo del 2012 (negación a pronunciarse sobre alegaciones), Rol No 2463-2012.

Tesorería Regional de Antofagasta, Fisco de Chile con Flota Barrios S.A. (2012): Corte Suprema, 6 de agosto del 2012 (modifica parecer anterior), Rol No4777-2010.

Celulosa Arauco y Constitución S.A. con Comisión Regional del Medio Ambiente (2013): Corte Suprema, 18 de enero de 2013 (Casación en la forma y en el fondo) Rol No10.045-2011.

Desarrollos URbanos S.A. contra la Dirección Ejecutiva del Servicio de EVAluación AmBIENTAL (2013): Segundo Tribunal Ambiental de Santiago, 9 de agosto de 2013 (recurso de reclamación), Rol R-4-2013.

Corporación Fiscalía del Medio Ambiente y otros con Comisión de EVALUaCión Ambiental del Servicio de Evaluación Ambiental de la Región de Aysén (2014): Corte de 
Apelaciones de Coyhaique 3 de abril del 2014 (acoge el recurso de protección), Rol No 56/2013.

Guacolda Adriana, Carrasco Pérez y otros con Endesa (2015): Corte Suprema, 22 de junio de 2015 (Casación en el fondo) Rol No23.652-2014.

Dictamen de la Contraloría General de LA República (1962): № 19.159, de 13 de abril de 1962

Dictamen de la Contraloría General de la República (1966): No 89.271, de 22 de noviembre de 1966.

Dictamen de la Contraloría General de la República (1969): № 62.000, de 29 de septiembre de 1969.

Dictamen de la Contraloría General de la República (1994): № 761, de 10 de enero de 1994.

Dictamen de la Contraloría General de la República (2001): o 25.505, de 9 de julio de 2001.

Dictamen de la Contraloría General de la República (2004): № 56.794, de 15 de noviembre de 2004.

Dictamen de la Contraloría General de la República (2005): № 38.004, de 16 de agosto de 2005.

Dictamen de la Contraloría General de la República (2006): № 34.810, de 28 de julio de 2006.

Dictamen de la Contraloría General de la República (2008): №59.709, 17 de diciembre de 2008.

Dictamen de la Contraloría General de la República (2009): № 910, de 08 de enero de 2009.

Dictamen de la Contraloría General de la República (2009): № 42.118, de 4 de agosto de 2009.

Dictamen de la Contraloría General de la República (2010): №33.078, de 18 de junio de 2010.

Dictamen de la Contraloría General de LA República (2015): № 40.245, de 19 de mayo de 2015. 